\title{
Moeda única no Mercosul
}

\author{
Currency union in Mercosul
}

HELDER FERREIRA DE MENDONÇA* ANABEL DA SILVA**

\begin{abstract}
RESUMO: Atualmente, influenciados pela experiência europeia, vários economistas brasileiros têm dado atenção especial à possibilidade de uma união monetária entre os países do Mercosul. Este trabalho faz uma breve análise dos principais aspectos teóricos que representam a base para a proposição de uma área monetária. Além disso, o artigo mostra duas visões distintas na literatura nacional sobre a hipótese da criação de uma área de moeda para o Mercosul. A principal conclusão deste artigo é que a proposta mencionada acima não é viável, porque os custos da coordenação macroeconômica são muito altos.

PALAVRAS-CHAVE: União monetária; Mercosul; sistema monetário.
\end{abstract}

ABSTRACT: Nowadays, influenced by the European experience, several Brazilian economists have given special attention to the possibility of a currency union among the countries of Mercosur. This paper makes a brief analysis of the main theoretical aspects that represent the basis for the proposition of a currency area. Besides this, the paper shows two distinct views in the national literature concerning the hypothesis of the creation of a currency area for the Mercosur. The main conclusion of this article is that the proposal mentioned above is not feasible, because the costs of macroeconomic coordination are too high.

KEYWORDS: Monetary union, Mercosur; monetary system.

JEL Classification: E42; F33.

"It appears likely that the number of currencies in the world, having proliferated along with the number of countries over the past 50 years, will decline sharply over the next two decades." (Rogoff, 2001: 243)

\footnotetext{
* Departamento de Economia da Universidade Federal Fluminense - UFF, Niterói/RJ, Brasil. E-mail: helderfm@hotmail.com.

* Departamento de Economia da Universidade Federal Fluminense - UFF, Niterói/RJ, Brasil, E-mail: ana_bel@ig.com.br. Submetido: março 2002; aceito: novembro 2002.
} 


\section{INTRODUÇÃO}

No período recente, diversos economistas brasileiros passaram a dar atenção especial à possibilidade da adoção de uma moeda única no Mercosul. A origem da discussão sobre o que os economistas chamam de "áreas monetárias ótimas" (AMO) teve origem com Robert Mundell (Prêmio Nobel de Economia de 1999) no início da década de 60, sendo posteriormente desenvolvida por McKinnon (1963) e Kenen (1969). Portanto, do ponto de vista teórico, a discussão não pode ser entendida como recente. Apesar de mais de 40 anos da existência da literatura sobre o tema, a única tentativa real de uso dessa estrutura é a União Monetária Européia ${ }^{1}$.

Para os países participantes de um bloco econômico a proposta de formação de uma área monetária representa uma alternativa aos regimes de câmbio fixo e flexível entre esses países, cujos impactos podem ser avaliados por meio de duas categorias básicas: i) efeitos microeconômicos — voltados para o problema de melhor alocação de recursos; e ii) efeitos macroeconômicos - que correspondem às políticas de estabilização da economia no curto prazo. A análise relativa às vantagens provenientes da adoção de uma moeda única está relacionada, sobretudo, à primeira categoria.

Para que se possam compreender as vantagens de uma moeda única é preciso lembrar que há uma relação estreita entre moeda e taxa de câmbio. Ademais, sob a perspectiva da eficiência microeconômica, a moeda tem como referencial as funções de meio de troca (voltada para realizar transações) e de unidade de conta (conversão de todos os preços na mesma moeda). Nas palavras de Laidler (1988, apud McCallum, 1996: 210):

"A single unit account economizes on record keeping and communications costs associated with trade: a single means of exchange economizes on the search costs that would, in its absence, be incurred in finding willing partners with whom to engage in barter; and further costs savings may be realized by using the means of exchange as a unit of account, hence reducing by half the number of relative prices in the economy. Furthermore, a 'nation' is a political entity with no self-evident significance for economics. As far as pure economic theory is concerned, trade is trade and that which happens to take place across political boundaries is no different from any other kind. Computational and transactions costs are smaller the smaller is the number of separate currencies involved in mediating trade, regardless of whether it is domestic, international, or a mixture of the two. It follows, then... that, from the point of view of [micro]economic efficiency, the best monetary arrangement for a world-wide economy is a single currency."

\footnotetext{
${ }^{1}$ Para o leitor interessado na análise sobre União Monetária Europeia, ver Rigolon e Giambiagi (1999) e Arestis et ali (2002).
} 
A análise acima não significa que a moeda como crédito não seja relevante para justificar uma união monetária. Alguns autores, como Davidson (1992-93), defendem o argumento de que uma união monetária (a nível mundial) seria profícua com base na idéia de complementaridade a ser buscada entre países e na necessidade de fornecimento supranacional de liquidez que permita estimular o desenvolvimento. A criação de um sistema monetário unificado seria capaz de neutralizar a incerteza associada às flutuações cambiais. Logo, poderiam ser evitados movimentos de capitais de regiões deficitárias para superavitárias. O ponto central para o bom funcionamento dessa estrutura seria o papel do Estado, via adoção de políticas de taxação e gastos que permitissem a redistribuição de liquidez. O objetivo seria reverter as assimetrias de balança comercial entre os países e os problemas de desigualdade do conjunto de países integrados, desenvolvendo a região como um todo (Amado e Mollo, 2002).

Este artigo tem por objetivo fazer um estudo sucinto dos principais fragmentos teóricos que constituem a base para a proposição de uma área monetária. Ademais, são apresentadas duas visões distintas na literatura nacional sobre a possibilidade de adoção de uma moeda única para o Mercosul. Além desta introdução, o trabalho apresenta-se estruturado da seguinte forma: a segunda seção apresenta a base teórica para a proposta de criação de uma área monetária ótima ressaltando sua conexão com a Teoria das Crises Monetárias (TCM) e a Teoria Fiscal da Determinação do Nível de Preços (TFDNP); a terceira seção faz uma digressão sobre a perspectiva da implantação de uma área monetária para o Mercosul; por último é apresentada a conclusão do artigo.

\section{ÁREAS MONETÁRIAS ÓTIMAS: O REFERENCIAL TEÓRICO}

Os argumentos econômicos para uma moeda comum são discutidos em termos da análise de uma AMO. O conceito de uma AMO foi criado por Mundell (1961). De acordo com o autor sobredito, a presença de crises periódicas no balanço de pagamentos de diversos países é resultado da combinação de taxas de câmbio fixas com a dificuldade de ajustamento devido à rigidez de preços e salários. Assim, um sistema de moedas nacionais conectadas por taxas de câmbio flexíveis representaria a estratégia mais adequada para facilitar o processo de ajustamento. Por esse dispositivo, uma depreciação da taxa de câmbio eliminaria o desemprego quando o balanço de pagamentos apresentasse déficit; por outro lado, uma apreciação eliminaria a inflação quando o balanço de pagamentos acusasse superávit.

Uma união monetária pressupõe uma única moeda e um único banco central (BC), o que, por conseguinte, gera a necessidade de uma oferta de meios de pagamento inter-regionais. Ademais, uma área monetária que compreenda mais de uma moeda depende da oferta internacional dos meios de pagamentos de todos os países que a compõem. Logo, nenhum BC pode aumentar suas responsabilidades mais rápido que outro sem perder reservas ou a conversibilidade da moeda. No caso de mais de uma área monetária no mundo isso implica a presença de taxas de câmbio 
variáveis. A principal justificativa para a adoção de taxas de câmbio flexíveis pode ser compreendida por meio do exemplo de uma relação comercial entre dois países (A e B). Admitindo-se um deslocamento da demanda de produtos do país B para os produtos do país $\mathrm{A}$, tem-se como efeito um nível de desemprego maior em $\mathrm{B}$ e uma inflação mais elevada em A. Nesta situação, a taxa de câmbio flexível funcionaria como um estabilizador automático - uma depreciação da moeda no país $\mathrm{B}$ (ou uma apreciação no país A) corrigiria o desequilíbrio externo e, além disso, reduziria o nível de desemprego em $\mathrm{B}$ e refrearia a inflação em A.

Sob a interpretação de Mundell (1961), o uso de um regime de câmbio fixo para uma AMO está condicionado a uma alta mobilidade geográfica dos fatores. Por outro lado, no caso de baixa mobilidade de fatores, a adoção do câmbio flexível seria o elemento responsável por garantir a mobilidade adequada entre as regiões. A imobilidade dos fatores entre duas regiões (considere $\mathrm{C}$ e $\mathrm{D}$ ) pode ser observada por meio de arranjos monetários. Se ambas as regiões têm a sua própria moeda, há maior flexibilidade e capacidade de cada região em conduzir políticas monetárias e fiscais na busca da estabilidade de preços. Entretanto, se a região D tem dificuldades para desenvolver indústrias que se encontram em C, então o movimento de fatores para $\mathrm{C}$ é o único meio de prevenir uma queda significativa da renda em D. Nesse sentido, uma política voltada para eliminar a imobilidade (presença de uma AMO) dos fatores entre $\mathrm{C}$ e $\mathrm{D}$ se mostraria adequada ${ }^{2}$.

De acordo com Mckinonn (1963), as AMOs são determinadas com base na análise da proporção dos bens comercializáveis e não-comercializáveis. A palavra "ótima” é utilizada para descrever

“(...) a single currency area within which monetary-fiscal policy and flexible external exchange rates can be used to give the best resolution of three (sometimes conflicting) objectives: (1) the maintenance of full employment; (2) the maintenance of balanced international payments; (3) the maintenance of a stable internal average price level." (McKinnon, 1963: 717)

Se a área em consideração é pequena, os preços dos bens comercializáveis (expressos em moeda externa) não são determinados pela taxa de câmbio. Ademais, o preço interno dos bens comercializáveis é mais influenciado pelo preço externo do que pelos preços dos bens não-comercializáveis. Destarte, as relações comerciais são imunes às políticas econômicas domésticas. Mckinnon (1963) analisa dois casos básicos:

(i) Maior proporção de bens comercializáveis - supõe-se o caso em que os bens exportáveis $\mathrm{X}_{1} \mathrm{e}$ os importáveis $\mathrm{X}_{2}$ constituem a maior parte do consumo doméstico e que o sistema de taxas de câmbio flexíveis é utilizado para manter o equilíbrio do

\footnotetext{
${ }^{2} \mathrm{O}$ argumento é reforçado pelo caso em que pequenas áreas tentam desenvolver indústrias por meio de economias de escala em vez de movimentar os fatores de forma eficiente em outra área.
} 
balanço externo. O preço dos bens não-comercializáveis $\left(\mathrm{X}_{3}\right)$, é mantido constante em relação à moeda doméstica e o preço dos bens comercializáveis varia no mesmo montante de uma mudança na taxa cambial. Desta forma, se a moeda doméstica é desvalorizada $10 \%$, os preços domésticos de $\mathrm{X}_{1}$ e de $\mathrm{X}_{2}$ aumentam $10 \%$, aumentando também em $10 \%$ o seu preço relativo a $\mathrm{X}_{3}$. De acordo com essa política, a produção de $\mathrm{X}_{1}$ e de $\mathrm{X}_{2}$ aumenta e o seu consumo diminui, melhorando o balanço de pagamentos. Nesse cenário, políticas monetárias e fiscais contracionistas podem complementar a queda da absorção. Não obstante, essas políticas só devem ser adotadas se o nível de desemprego for pequeno, pois políticas monetárias e fiscais contracionistas têm como efeito a redução da produção e um aumento no nível de desemprego, capazes de neutralizar os benefícios obtidos no balanço de pagamentos.

O exemplo acima é importante, pois revela que flutuações na taxa de câmbio para deslocar a demanda por exportações ou importações não são compatíveis com o objetivo de manter a estabilidade do nível de preços em uma economia com elevado grau de abertura. No caso de a economia estar próxima ao nível de pleno emprego, uma melhora da balança comercial deve ser acompanhada por uma queda na absorção (promovida, por exemplo, por meio de uma elevação dos impostos), para que os preços de $\mathrm{X}_{3}$ permaneçam constantes em relação à moeda doméstica. De acordo com essa concepção, quanto mais aberta uma economia, um sistema de taxas de câmbio flexíveis torna-se menos eficiente para o controle do balanço externo e é prejudicial para a estabilidade dos preços internos. Assim, o uso de taxas de câmbio fixas seria mais conveniente. Ainda que em um primeiro momento ocorresse queda na absorção promovida pelo retrocesso do setor dos bens não-comercializáveis, no longo prazo, devido ao aumento da produção dos bens comercializáveis, o desemprego se reduziria.

(ii) Maior proporção de bens não-comercializáveis - neste caso, uma desvalorização da moeda em $10 \%$ acarreta um aumento do preço de $\mathrm{X}_{1}$ e de $\mathrm{X}_{2}$ em $10 \%$, mas o efeito sobre o preço doméstico é menor do que na situação em que há maioria de bens comercializáveis.

O aumento no preço relativo dos bens comercializáveis tem por objetivo o estímulo à produção de forma que seja obtida uma melhora no saldo da balança comercial. Destarte, se políticas monetárias e fiscais contracionistas forem utilizadas com o objetivo de incrementar o superávit da balança comercial, haverá uma redução na absorção doméstica implicando um aumento no nível de desemprego. Como o impacto da queda da absorção é maior nas indústrias dos bens não-comercializáveis do que nas de bens comercializáveis, se houver qualquer rigidez na mobilidade dos recursos, a balança comercial não melhora de forma imediata. Logo, antes do aumento na produção de $\mathrm{X}_{1} \mathrm{e} \mathrm{X}_{2}$, é preciso que ocorra uma redução nos preços de $\mathrm{X}_{3}$. Contudo, a redução do preço de $\mathrm{X}_{3}$ tem um grande impacto sobre o nível dos preços domésticos. Admitindo-se o uso de um regime de câmbio fixo e o caso de uma pequena proporção de bens comercializáveis (situação próxima a de uma economia fechada), políticas monetárias e fiscais contracionistas são eficientes para eliminar um déficit da balança comercial, pois a maior parte da produção de bens comercializáveis passa a ser destinada às exportações. 
De acordo com a atual visão mainstream da política econômica, o principal objetivo da política monetária consiste na busca da estabilidade do valor da moeda. Em consonância com essa concepção, Mckinnnon (1963) destaca cinco implicações provenientes da liquidez:

(i) mudanças nos preços relativos entre bens comercializáveis e não-comercializáveis;

(ii) condução da política monetária de forma a manter o equilíbrio do balançoexterno;

(iii) minimização do custo real necessário para preservar o balanço externo,concomitante à necessidade de minimizar as flutuações sobre o nível de preços domésticos;

(iv) condução da política monetária com o objetivo de encontrar uma moedaestável cuja propriedade de liquidez seja preservada; e

(v) sob um sistema capitalista, a quantidade de moeda (numerário) e a liquidezsão elementos importantes para impedir problemas para a acumulação de capital e poupança ${ }^{3}$.

Considerando uma pequena área, cuja produção tenha uma maior proporção de bens comercializáveis, e que os preços são determinados pela moeda doméstica, observa-se que a decisão de ancorar a moeda aos bens não-comercializáveis não é eficiente. Os bens importáveis podem ser mais representativos, e uma moeda ancorada a esses bens pode ter uma maior liquidez ${ }^{4}$. Assim, se a moeda de uma pequena área monetária não é ancorada a uma grande área e se sua liquidez é menor, os poupadores acumulam dinheiro na moeda mais líquida. Esse movimento ocorre mesmo quando a eficiência marginal do investimento da pequena área é maior do que o investimento externo. Por conseguinte, pequenos países com moedas fracas tendem a financiar o déficit do balanço de pagamentos de países que possuem moedas mais demandadas 5 .

Em contraposição ao que foi dito acima, observa-se que a variabilidade dos fluxos de capitais de curto prazo entre moedas com liquidez próximas é menor com taxas de câmbio flexíveis, uma vez que os riscos cambiais e a liquidez são equivalentes. Assim, a divisão do mundo em áreas monetárias de tamanho ótimo faria com que o fluxo de capitais de curto prazo se distribuísse de forma mais equilibrada entre as regiões, contribuindo para que as políticas monetárias dessas áreas fossem utilizadas para o alcance de um segundo objetivo - o pleno emprego.

A partir da identificação feita por Mundell (1961) do trade-off, maior eficiência microeconômica e menor possibilidade de resposta a choques que afetam de

\footnotetext{
${ }^{3}$ Um problema potencial para este caso, refere-se à situação em que há uma demanda mais elevada pela moeda de uma área monetária maior.

${ }^{4}$ É preciso salientar que a estratégia de ancorar a moeda de uma pequena área monetária aos bens importados de uma grande área externa é o mesmo que ancorar a moeda doméstica a uma moeda externa.

${ }^{5}$ Essa situação é importante para ilustrar como Mckinnon (1963) mostra que o sistema de taxas de câmbio flexível só é eficiente para a manutenção do balanço externo quando a liquidez da moeda é da mesma ordem que a das moedas mais demandadas no mundo.
} 
forma distinta uma AMO, alguns autores como Obstfeld e Rogoff (1996) e McCallum (1999) identificaram os principais benefícios e custos potenciais oriundos da adoção de uma AMO (vide tabela 1).

Além dos argumentos tradicionais que caracterizam o cerne do debate sobre uma união monetária, nos anos 90 a literatura sobre a Teoria das Crises Monetárias (TCM) tornou-se um tópico importante para análise. A justificativa para o aumento da importância da TCM reside no fato de que os fluxos financeiros internacionais não são regulados. Portanto, a escolha relevante para boa parte das economias deve ser feita entre a adoção de um regime de taxa de câmbio flexível ou a participação em uma união monetária ${ }^{6}$.

O modelo original sobre a TCM foi desenvolvido por Flood e Garber (1984). Nesse modelo é admitido que, para a manutenção do regime de câmbio fixo, o estoque de moeda (base monetária) deve permanecer constante. Como a base monetária é resultado da soma entre o crédito doméstico e o estoque de reservas estrangeiras, no caso de o governo necessitar de uma taxa de crescimento do crédito doméstico para satisfazer outros objetivos além de manter estável a taxa de câmbio, isto implica uma queda nas reservas. Logo, se for mantida a taxa de crescimento de crédito necessária para os objetivos do governo, a manutenção do regime de câmbio fixo torna-se insustentável ${ }^{7}$.

Tabela 1: Custos e benefícios potenciais de uma AMO

\begin{tabular}{|c|c|c|}
\hline & Benefícios & Custos \\
\hline I & $\begin{array}{l}\text { Redução dos custos de transação devido à } \\
\text { desnecessidade de conversão da moeda. }\end{array}$ & $\begin{array}{l}\text { Os países integrantes da área renunciam } \\
\text { ao uso da política monetária em } \\
\text { resposta a choques macroeconômicos. }\end{array}$ \\
\hline II & $\begin{array}{l}\text { Redução dos custos contábeis e maior capacidade } \\
\text { de predizer os preços relativos por firmas que } \\
\text { realizam negócios em ambos os países. }\end{array}$ & $\begin{array}{l}\text { As regiões pertencentes a uma união } \\
\text { monetária podem utilizar a inflação para } \\
\text { reduzir a carga real do déficit público. }\end{array}$ \\
\hline III & $\begin{array}{l}\text { Isolamento de choques monetários e bolhas } \\
\text { especulativas que possam gerar flutuações } \\
\text { temporárias na taxa de câmbio. }\end{array}$ & $\begin{array}{l}\text { O surgimento de problemas políticos e } \\
\text { estratégicos na divisão das receitas de } \\
\text { senhoriagem entre os países. }\end{array}$ \\
\hline IV & $\begin{array}{l}\text { Menor pressão política por proteção comercial } \\
\text { devido aos significativos deslocamentos na taxa } \\
\text { de câmbio real. }\end{array}$ & $\begin{array}{l}\text { O problema de evitar ataques } \\
\text { especulativos na transição das moedas } \\
\text { individuais para uma moeda única. }\end{array}$ \\
\hline V & $\begin{array}{l}\text { Maior integração entre os mercados financeiros e não- } \\
\text { financeiros em dois países sob uma moeda comum. }\end{array}$ & \\
\hline
\end{tabular}

Deve-se ressaltar que, no caso onde há previsão perfeita, a taxa de câmbio fixa entra em colapso antes que o estoque de reservas estrangeiras caia a zero. Assim,

\footnotetext{
${ }^{6}$ A opção por um regime de taxa de câmbio fixa (mas ajustável) é improvável, pois este regime cambial é sujeito a ataques especulativos, podendo ocorrer abruptas perdas de reservas e depreciações cambiais mesmo na ausência de choques.

${ }^{7}$ Considerando uma situação real, as autoridades mantêm um nível negativo ou positivo de reservas após o colapso do regime de câmbio fixo. No caso do modelo em consideração, é suposto que o nível de reservas após o colapso é nulo.
} 
na ausência de uma intervenção oficial, prevalece uma taxa de câmbio flexível que tende a se depreciar ao longo do tempo. Porém, com expectativas racionais, os agentes sabem, de forma prévia, que a taxa de câmbio tende a se depreciar e, dessa forma, antes que isso ocorra, vendem a moeda doméstica, adquirindo reservas da moeda estrangeira.

De acordo com o modelo Flood-Garber (1984), quando o regime de taxa de câmbio fixo entra em colapso, este é substituído por um regime de câmbio flexível, que é mantido de forma indefinida. Sob essa estrutura, é admitido que a crise monetária é deflagrada quando os agentes, via substituição da moeda doméstica (aquisição de reservas do $\mathrm{BC}$ ), provocam uma queda abrupta nas reservas estrangeiras. Ademais, a mudança do regime de câmbio acarreta uma elevação na taxa de inflação esperada e, por conseguinte, da taxa nominal de juros, fazendo com que os detentores de ativos fiquem satisfeitos com a redução no estoque de moeda em circulação.

O modelo supracitado explica como ocorrem perdas de reservas pelo BC, a elevação da taxa de juros e a mudança para um regime de taxa de câmbio flexível quando ocorrem crises monetárias. Além disso, por considerar a taxa de crescimento da base monetária e a taxa de câmbio como sendo funções determinísticas do tempo, o modelo é capaz de precisar quando ocorrerá o colapso. Não obstante, o modelo não explica (de fato) a ocorrência do fenômeno, visto que a hipótese inicial consiste na preocupação do governo em manter uma taxa de câmbio fixa concomitante a outra atividade política que é incompatível com essa estratégia. Logo, é óbvio que o governo terá que fazer a opção entre manter o regime de câmbio fixo ou fazer a opção pelo outro objetivo.

Garber e Svensson (1995) e Obstfeld e Rogoff (1995) analisaram a viabilidade de um regime de taxa de câmbio fixa, mas potencialmente ajustável. De acordo com Garber e Svensson, um BC pode impedir o colapso do regime de taxa de câmbio fixa por meio da combinação de altas taxas de juros e contração da base monetária. Para Obstfeld e Rogoff, os bancos centrais têm acesso a reservas suficientes para superar os ataques especulativos e, assim, manter a taxa de câmbio fixa ao longo do tempo. Apesar disso, os autores supracitados advertem que o regime de câmbio fixo não deve ser entendido como uma política incondicional, pois os bancos centrais tomam decisões considerando o que está acontecendo no resto da economia. Portanto, havendo incompatibilidade entre o regime de câmbio fixo e as políticas domésticas necessárias para manter o bom funcionamento da economia, as últimas prevalecem.

Quanto à análise sobre uma associação monetária, McCallum (1999: 17-18) define que:

"The creation of a currency board gives rise to an institution that is more difficult and costly to dismantle, when it interferes with some other policy objective, than a more conventional fixed-rate arrangement. But unless maintenance of the currency board arrangement has priority over all other macroeconomic objectives, eventually the currency board, too, 
will break down. The same might even be said for membership in a currency union, but the costs of departing from a union are presumably even greater than those from the termination of a currency board. The other members of the union might conceivably even go to war to prevent its breakup."

Outra agregação importante para o debate sobre uma união monetária referese ao papel que a política fiscal exerce sobre a determinação do nível de preços. $\mathrm{O}$ difundido argumento de que o objetivo do $\mathrm{BC}$ deve ser a busca da estabilidade de preços tem como referência teórica o argumento friedmaniano de que a inflação é um fenômeno monetário. No período recente, uma nova perspectiva acerca da determinação do nível de preços baseada na política orçamentária da autoridade fiscal tem emergido - trata-se da Teoria Fiscal da Determinação do Nível de Preços (TFDNP). Sob essa perspectiva, a adoção de um BC independente não bastaria para garantir a estabilidade de preços, também seria necessária uma política fiscal adequada. A TFDNP pode ser dividida em duas versões (Carlstrom e Fuerst, 2000): (i) Versão fraca - destaque para a relação entre as políticas monetária e fiscal no caso de dominância fiscal. A autoridade fiscal define os déficits e superávits no presente e no futuro sem consultar a autoridade monetária e, portanto, determina o montante de receita proveniente da venda de títulos e senhoriagem. Neste caso, a autoridade monetária diante da restrição imposta pela demanda por títulos do governo tende a financiar, via senhoriagem, o restante da receita necessária para satisfazer a demanda da autoridade fiscal. Sob essa perspectiva, há a tendência de que o responsável pela política não mantenha o equilíbrio fiscal devido à expectativa de que o $\mathrm{BC}$ garantirá os recursos necessários para satisfazer os gastos realizados. Assim sendo, o provável resultado é o aumento do déficit em decorrência do aumento dos gastos e o conseqüente aumento da taxa de inflação derivado da emissão monetária pelo BC.

(ii) Versão forte - a política fiscal determina a inflação futura independente do comportamento da política monetária. Esta interpretação assume que a restrição orçamentária e, portanto, a política fiscal, induzem a um menor nível de preço inicial. A principal diferença em relação à versão fraca advém do fato de que ambas as políticas fiscal e monetária são determinadas de forma exógena e que os preços se ajustam para garantir a solvência das políticas.

As economias que visam a uma união monetária possuem governos diferentes e, por conseguinte, autoridades fiscais distintas. Em conseqüência, a relação entre políticas monetárias e fiscais se torna relevante. Nesse sentido, a discussão sobre a TFDNP e sua relação com a Teoria Monetarista executa um papel fundamental na análise econômica sobre união monetária ${ }^{8}$. A teoria desenvolvida por autores como

\footnotetext{
${ }^{8}$ De acordo com a hipótese monetarista, no caso de uma economia em que o estoque de moeda é constante e não há choques que influenciam os agentes ou o processo produtivos, os agentes privados não compram títulos do governo e o nível de preços é constante ao longo do tempo com um valor
} 
Sims (1994), Woodford (1996) e Cochrane (1998), argumenta que a determinação do nível geral de preços é um fenômeno fiscal, e não monetário. Sob essa interpretação, o nível de preços segue a taxa de crescimento dos títulos do governo, não possuindo nenhuma relação com a taxa de crescimento do estoque de moeda. Destarte, de acordo com a TDFNP o processo de unificação monetária deve ser precedido de uma harmonização das políticas fiscais dos países integrantes da região monetária para que o objetivo da estabilidade de preços seja assegurado.

Os pontos teóricos analisados nesta seção revelam que a concentração das vantagens oriundas da adoção de uma moeda única para os países integrantes de um bloco econômico tem como justificativa o incremento na eficiência microeconômica. Não obstante, para que possa ser observada essa vantagem é preciso que os países formadores do bloco passem por um processo de integração econômica. Portanto, a variável-chave para análise da viabilidade da adoção de uma moeda única tem como fator condicionante a harmonização das políticas econômicas dos diversos países que compõem o bloco. Em outras palavras, os possíveis benefícios provenientes de uma moeda única sobrevêm aos necessários ajustes de natureza macroeconômica. A próxima seção tem como objetivo observar em que medida os países integrantes do Mercosul estão tendo êxito para cumprir a primeira etapa que levaria à possibilidade de implementar uma moeda única.

\section{MERCOSUL: DIGRESSÕES SOBRE UMA POSSÍVEL UNIFICAÇÃO MONETÁRIA}

O primeiro passo rumo à integração dos países participantes do Mercosul $^{9}$ foi a formação de uma União Aduaneira parcial ${ }^{10}$, tendo como principal mecanismo regulador a Tarifa Externa Comum (TEC). A TEC foi criada com o objetivo de dar maior estabilidade à estrutura de proteção comercial, visto que ela diminui a liberdade dos países na condução da política comercial contribuindo para a redução das assimetrias quanto à alocação de recursos e de incentivos ao investimento para o bloco econômico.

O principal resultado obtido em cerca de dez anos de discussão sobre a eliminação de barreiras comerciais na região foi o grande aumento no comércio bilateral Brasil-Argentina (aproximadamente 90\% do comércio intraMercosul). Ainda que tenham ocorrido progressos no aspecto comercial, não se pode dizer que a primeira fase para a criação de uma área monetária esteja consolidada. Nos últimos

\footnotetext{
proporcional à magnitude do estoque de moeda. Por outro lado, pela hipótese fiscalista, com o estoque de moeda constante, o estoque de títulos e o nível de preços explodem com o passar do tempo.

${ }^{9}$ Inicialmente constituído por Argentina, Brasil, Paraguai e Uruguai.

${ }^{10}$ Eliminação parcial dos direitos alfandegários e outras restrições comerciais em relação às importações originárias de parceiros do acordo e que possuem políticas comerciais comuns para os produtos provenientes de terceiros países.
} 
anos, as dificuldades enfrentadas por Brasil e Argentina devido aos choques externos demonstraram que os países formadores do bloco nem sequer possuem uma estrutura que possa ser entendida como uma verdadeira zona de livre comércio ${ }^{11}$.

Apesar das dificuldades enfrentadas, é esperado que a União Aduaneira parcial no Mercosul tenda a avançar para uma maior integração econômica, fazendo com que seja necessária a coordenação das políticas macroeconômicas dos países envolvidos. Conforme estabelecido no Tratado de Assunção (1992), o Mercosul constituirá uma União Aduaneira em que haverá a coordenação de políticas industriais, tecnológicas e regionais com o objetivo de fazer convergir de forma gradual as políticas macroeconômicas fiscal, monetária e cambial.

Em geral, a literatura que trata da coordenação de políticas tem destacado o conceito de harmonização como um indicativo do comprometimento existente entre os países envolvidos em um processo de integração econômica. Sob esse aspecto, são destacados quatro fatores que revelam o maior ou menor envolvimento dos países que intencionam constituir um bloco econômico (Fernández e González, 1996):

— o intercâmbio de informações relevantes entre os governos (de fundamental importância para o processo de tomada de decisões);

- a existência de acordos sobre objetivos que convirjam para os do programa de integração $0^{12}$; bais; e

— verificar a adoção de medidas específicas no que se refere às políticas glo-

- substituição de políticas discricionárias ou da aplicação de políticas individuais pela adoção de políticas regionais. Neste caso, a coordenação das políticas supranacionais tem prioridade sobre as políticas nacionais ${ }^{13}$.

Uma importante questão que emerge quando se analisa a coordenação de políticas macroeconômicas consiste em identificar qual é a causa que estimula os governos de diversos países a participar de um processo de integração econômica. De forma sucinta, pode-se dizer que a motivação para esse procedimento concentra-se em três elementos-chave:

“a) la posibilidad de ampliar los mercados y los flujos de comercio entre los países socios aumentando el bienestar general de la región. El primer caso implica la posibilidad de explotar economías de escala y de extensión en los diversos países miembros, ampliando la competencia de mercados y reduciendo costos de producción.

\footnotetext{
${ }^{11}$ Mesmo que união aduaneira, excluindo-se políticas comerciais comuns para os produtos provenientes de terceiros países.

12 De acordo com Garriga \& Sanguinetti (1996), estes dois primeiros níveis de harmonização não implicam restrições sobre as políticas domésticas e são denominadas formas flexíveis de coordenação.

${ }^{13}$ Um exemplo de coordenação completa no campo monetário, refere-se à existência de uma única moeda no mercado comum e política monetária controlada por um Banco Central Supranacional. O caso real mais próximo dessa situação corresponde à União Monetária Européia.
} 
b) el intento de establecer mecanismos preventivos sobre "derrames" ocasionados por cambios de precios o cantidades de un país sobre otro. (...)

(c) efecto 'disciplinador' o compra de reputación. En rol que posee elcumplimiento de compromisos supranacionales, regionales, puede ser importante para que los países implementen ciertas políticas que de otra forma no hubieran hecho.” (Fernández e González, 1996: 99-100)

Deve-se destacar que no processo de integração, o intercâmbio de bens e serviços aparece como resultado tanto das políticas comerciais quanto da evolução macroeconômica dos países envolvidos. Ademais, o efeito "derrame" faz com que problemas internos de uma economia sejam transmitidos, via preços e quantidades, a outras economias que estão vinculadas por meio de fluxos comerciais e financeiros.

Em relação à proposição de uma unificação monetária no Mercosul duas visões distintas têm sido observadas na literatura nacional. Rigolon e Giambiagi (1999) representam um exemplo de autores que são favoráveis à integração monetária para o longo prazo. De acordo com a interpretação dos autores sobreditos, a adoção de um BC independente para a região seria capaz de promover uma maior credibilidade em relação às políticas monetárias, tendo como resultado, uma redução no viés inflacionário das políticas domésticas.

Outro ponto a ser ressaltado, refere-se ao fato de que a probabilidade do financiamento inflacionário de déficits orçamentários e a capacidade de os governos produzirem déficits insustentáveis seriam menores. Além disso, a estabilidade de preços associada a uma maior disciplina fiscal teria como resultado a manutenção do valor interno e externo da moeda, o que, por sua vez, acarretaria menor incerteza cambial em relação ao resto do mundo e taxas de juros mais adequadas para promover o investimento produtivo e o crescimento econômico. Por último, conforme ressaltado na seção anterior, a adoção de uma moeda única promoveria uma queda dos custos de transação e de conversão de moedas e, além disso, reduziria a capacidade de as indústrias discriminarem preços em mercados segmentados. Como conseqüência, isso estimularia a ampliação dos fluxos comerciais, de serviços, e uma elevação da eficiência microeconômica.

A principal justificativa para a adoção de uma AMO para o Mercosul, sob a perspectiva dos autores sobreditos, advém do fato de que o histórico das economias formadoras do bloco não é capaz de transmitir aos agentes privados confiança para a manutenção do valor da moeda no longo prazo. Destarte, o objetivo de criar uma união monetária seria o de romper com o passado de instabilidade que caracterizou essas economias e instituir uma moeda que tenha valor.

Conforme reconhecido por Rigolon e Giambiagi (1999), a proposta de unificação monetária no Mercosul é alvo de duas críticas: (i) os países participantes não satisfazem os requisitos de uma $\mathrm{AMO}$; e (ii) a renúncia às políticas monetária e cambial domésticas implicaria custos elevados. Entretanto, os autores supracitados atenuam a primeira crítica alegando que os critérios para a formação de uma AMO podem ser satisfeitos ex post. Quanto à segunda crítica, os custos mais elevados 
referem-se à perda da capacidade de responder a choques no produto, à inflação e ao balanço de pagamentos quando as economias são muito diferentes, pouco abertas e possuem menos instrumentos alternativos de ajuste, tal como a mobilidade do trabalho. Contudo, esses custos podem se reduzir no longo prazo devido a três pontos básicos: (i) com a integração comercial, as economias do Brasil e da Argentina tendem a se tornar mais similares; (ii) há uma tendência a uma maior abertura das economias da região; e (iii) a integração econômica deve expandir a flexibilidade dos salários reais e a mobilidade da mão-de-obra na região.

Ao contrário da visão de Rigolon e Giambiagi (1999), autores como Pastore e Pinotti (2000) não são entusiastas à proposta de unificação monetária para os países integrantes do Mercosul. De acordo com a interpretação dos últimos autores mencionados, existem duas alternativas para o processo de adoção de uma moeda única para a região: (i) generalização do currency-board que fora adotado pela Argentina até o período recente; e (ii) durante a transição para a moeda única, fixar as paridades entre as moedas dentro da área evitando atrelar a fixação ao dólar.

Conforme indicado pelos autores supracitados, e confirmado pela crise Argentina a partir de 2001, as deficiências inerentes a um regime de currency board fazem com que a primeira alternativa não seja factível ${ }^{14}$. Pastore e Pinotti (2000) advertem que, apesar de a segunda alternativa mostrar-se atraente, há custos significativos para a construção de instituições monetárias supranacionais. Outro fato contrário à proposição de uma moeda única, refere-se à necessidade da coordenação de políticas macroeconômicas por um grupo de países que não conseguem cumprir suas próprias metas individuais.

Dado que em uma AMO o câmbio deve ser fixo apenas no caso de existir mobilidade de mão-de-obra (Mundell, 1961), a principal justificativa técnica para a não-viabilidade de uma área monetária para o Mercosul pode ser compreendida nos seguintes termos:

"Se não existirem as variações cambiais que reduzem, ou eliminam, os efeitos do desemprego de um país sobre os demais, as flutuações cíclicas de um país contaminarão os outros. Para não 'importar' este desemprego, os demais países da união monetária teriam que derrubar os salários que, no entanto, são rígidos. O regime cambial que minimiza as flutuações cíclicas comuns aos países do Mercosul é, dentro da teoria das áreas monetárias ótimas, o de câmbio flexível, e não de câmbio fixo. Os países que compõem o NAFTA podem ser uma área monetária ótima, mas não o Mercosul.” (Pastore e Pinotti, 2000)

Além dos argumentos apresentados pelos autores acima, deve-se ressaltar que os bancos centrais dos dois principais países do bloco não possuem credibilidade

\footnotetext{
${ }^{14} \mathrm{O}$ sucesso na introdução de currency board demanda um sistema financeiro saudável, uma autoridade fiscal responsável e um mercado de capitais com razoável eficiência. Para uma análise dos prós e contras sobre a utilização de um currency board, ver Mendonça (2002).
} 
suficiente para desempenhar o papel de líder natural durante um processo de unificação monetária. Assim, de forma diferente do caso da União Européia, em que países como Itália e Bélgica “compraram” reputação do Bundesbank por meio do European Rate Market, o Mercosul não possui uma instituição que seja dotada de credibilidade suficiente para exercer papel semelhante ao do Bundesbank. Um outro ponto que se mostra contrário à adoção de uma moeda única para os países integrantes do Mercosul diz respeito ao fato de que ela não seria capaz de atenuar as incertezas macroeconômicas que caracterizam a região. Uma nova moeda para o bloco (similar ao Euro) não seria adequada, pois a falta de credibilidade dos países que compõem a região faria com que ocorressem flutuações significativas da moeda local em relação às demais. Por conseguinte, haveria a possibilidade de que estratégias individuais para a condução da política monetária apresentassem resultados superiores àqueles a serem obtidos pela área monetária.

Outro aspecto que se mostra contrário à adoção de uma moeda única para o Mercosul diz respeito ao aumento do risco de contágio para os países integrantes da área monetária. Dado que os países que compõem o Mercosul são caracterizados pelo insucesso na condução da política econômica, a adoção de uma moeda única poderia promover uma espécie de círculo virtuoso às avessas. Dado que o número de países que integram o bloco é muito reduzido (apenas quatro), não há uma grande economia capaz de neutralizar as possíveis adversidades sobre a região e haveria o aumento da interdependência entre essas economias; é provável que as sucessivas crises que caracterizam os países participantes do Mercosul viessem a minar a credibilidade do bloco econômico.

\section{CONSIDERAÇÕES FINAIS}

O principal entrave à implantação de uma moeda única diz respeito à dificuldade para harmonizar as diferenças entre os diversos países que integram a área monetária. Os argumentos apresentados na seção anterior remetem a uma importante reflexão: caso venha a ocorrer uma união monetária no Mercosul, devido às características particulares da região, o modelo a ser instalado não deverá seguir o adotado pela União Monetária Européia, visto que não há credibilidade suficiente no bloco para que possa ser efetuada a transição. Conforme declarado pelo então diretor de Política Econômica do Banco Central do Brasil no ano de 2000 - Sérgio Werlang - a convergência das políticas macroeconômicas entre os países que formam o Mercosul representa uma "precondição para a convivência da estabilidade das economias”. Ou seja, a coordenação é o nó cego a ser desatado para que seja possível vislumbrar a possibilidade de adoção de uma moeda comum para o bloco econômico.

Nesse sentido, deve haver um esforço em se pensar qual será a forma mais 
adequada para que ocorra o processo de coordenação, ou até mesmo ponderar se a tentativa de adotar uma moeda única no longo prazo é merecedora de atenção ${ }^{15}$.

De acordo com Pastore e Pinotti (2000: 23),

"A recomendação de uma moeda única para o Mercosul não faz nenhum sentido... Ela nos parece mais um modismo, que desvia a atenção dos verdadeiros problemas em vez de auxiliar a concentração na sua solução."

Outro ponto a ser realçado é que antes de se imaginar a possibilidade do uso de uma moeda única, é importante lembrar que a integração dos países formadores do Mercosul demanda uma série de elementos voltados para sua infra-estrutura (estradas, portos, aeroportos, ferrovias etc.) que necessitam da ação coordenada entre os governos para melhorar a capacidade produtiva do bloco econômico. Ademais, a coordenação macroeconômica não pode ser entendida como um processo indolor para os países integrantes da possível área monetária. Os custos provenientes da perda da liberdade do uso de políticas discricionárias frente aos choques macroeconômicos podem acarretar uma piora do bem-estar aos cidadãos do Mercosul.

\section{BIBLIOGRAFIA}

AMADO, A.M. \& MOLLO, M.L.R. "A Análise Heterodoxa da Formação de Blocos Regionais e o Pensamento da CEPAL”. Anais do VII Encontro Nacional de Economia Política, CD-Rom, Maio, 2002.

ARESTIS, P., FERRARI, F., de PAULA, L.F., SAWYER, M. "The Euro and the EMU: Lessons for Mercosur". Anais do VII Encontro Nacional de Economia Política, CD-Rom, Maio, 2002.

CARLSTROM, C.T. \& FUERST, T.S. “The Fiscal Theory of the Price Level”, Economic Review, Federal Reserve Bank of Cleveland, 36 (1).

COCHRANE, J. H. “A Frictionless View of U.S. Inflation”, NBER Macroeconomics Annual. Cambridge, MA: MIT Press, 1998.

DAVIDSON, P. “Reforming the World's Money”, Journal of Post Keynesian Economics 15 (2), Winter, 1992-93.

DRAZEN, A. "Political Economy in Macroeconomics". Princeton University Press, 2000.

EUROPEAN CENTRAL BANK. "The Monetary Policy of the ECB”, 2001.

FERNÁNDEZ, R. \& GONZÁLEZ, G. "La Coordinación de Políticas Macroeconómicas y el Mercosur”. Contribuciones 4/1996 - CIEDLA. Fundación Konrad Adenauer.

FLOOD, R.P., \& GARBER, P.M. “Collapsing Exchange-Rate Regimes: Some Linear Examples”, Journal of International Economics, 17, 1984a.

\footnotetext{
${ }^{15}$ No caso específico da coordenação de políticas podem-se encontrar três tipos: (i) coordenação da política monetária - podendo ser feita por meio de uma regra à la Friedman, isto é, pela determinação de uma taxa de expansão dos agregados monetários; (ii) coordenação de políticas fiscais — pela redução dos déficits públicos a um determinado percentual do PIB (o Tratado de Maastricht é um bom exemplo, no qual foi estabelecido que os países integrantes da União Monetária não deverão ter um déficit superior a $3 \%$ do PIB e que o grau de endividamento dívida pública/PIB não deve ultrapassar $60 \%$.); e (iii) coordenação da política cambial - pela determinação de uma banda estabelecida sobre algum tipo de câmbio real ou nominal como âncora.
} 
FLOOD, R.P., \& GARBER, P.M. “Gold Monetization and Gold Discipline”, Journal of Political Economy, 92, 1984b.

GARBER, P.M. \& L. E. O. SVENSSON, "The Operation and Collapse of Fixed Exchange Rate Regimes", Handbook of International Economics. G. Grossman and K. Rogoff (eds.) Amsterdam: North Holland, 1995.

GARRIGA, M. \& SANGUINETTI, P. “Coordinación Macroeconómica en el Mercosur: Ventejas, desventejas y la Práctica.” Prosur, Fundación Friedich Ebert, Buenos Aires, 1996.

KENEN, P. "The Theory of Optimum Currency Areas: an Ecletic View. In: Mundell, R. \& Swoboda, A. (eds.), Monetary problems of the international economy. University of Chicago Press, 1969.

LAIDLER, D.P. "What Remains of the Case for Flexible Exchange Rates?" Pakistan Development Review, 27, Winter, 1988.

MCCALLUM, B.T. “Theoretical Issues Pertaining to Monetary Unions”, NBER Working Paper, $\mathrm{n}^{\circ}$ 7393, 1999.

MCCALLUM, B.T. “International Monetary Economics”. New York, Oxford University Press, 1996.

MCKINNON, R. I. “Optimum Currency Areas”, American Economic Review, 53, 1963.

MENDONÇA, H.F. "Regimes Monetários e a Busca da Estabilidade de Preços: o Uso de Metas para a Taxa de Câmbio, Agregados Monetários e Inflação.” Revista de Economia Política, 22 (1) (85), janeiro-março, 2002.

MUNDELL, R. A. “A Theory of Optimum Currency Areas”, American Economic Review, 51 (4), 1961. OBSTFELD, M., \& K. ROGOFF, "Foundations of International Macroeconomics". Cambridge, MA: MIT Press, 1996.

OBSTFELD, M., \& K. ROGOFF “The Mirage of Fixed Exchange Rates”, Journal of Economic Perspectives, vol. 9, 1995.

PASTORE, A.C. \& PINOTTI, M.C. “Globalização, Fluxos de Capitais e Regimes Cambiais: Reflexões sobre o Brasil”, Estudos Econômicos, 30 (1), janeiro, 2000.

RIGOLON, F. \& F. GIAMBIAGI, “Áreas Monetárias Ótimas: Teoria, Unificação Monetária Européia e Aplicações para o Mercosul”, Economia Aplicada, 3, São Paulo: FEA-USP/FIPE, Março, 1999. ROGOFF, K. "Why Not a Global Currency?” American Economic Review, 91 (2), May 2001.

SIMS, C. A. "A Simple Model for the Study of the Determination of the Price Level and the Interaction of Monetary and Fiscal Policy”, Economy Theory 4, 1994.

WOODFORD, M. “Control of the Public Debt: A Requirement for Price Stability?”, NBER Working Paper, 1996. 